\title{
Beneficial influence of dietary spices on the ultrastructure and fluidity of the intestinal brush border in rats
}

\author{
Usha N. S. Prakash and Krishnapura Srinivasan* \\ Department of Biochemistry and Nutrition, Central Food Technological Research Institute, CSIR, Mysore 570 020, India
}

(Received 9 September 2009 - Revised 1 December 2009 - Accepted 7 January 2010 - First published online 24 February 2010)

The beneficial influence of three common spices was examined in experimental rats on: (i) the membrane fluidity of intestinal brush-border membranes (BBM), (ii) the activity of intestinal membrane-bound enzymes, and (iii) ultrastructural alterations in the intestinal epithelium. Groups of male Wistar rats were maintained on dietary black pepper $(0.5 \%)$, red pepper $(3.0 \%)$, ginger $(0.05 \%)$ and spice bioactive compounds piperine $(0.02 \%)$ and capsaicin $(0.01 \%)$ for 8 weeks. A membrane fluidity study using an apolar fluorescent probe showed increased BBM fluidity in all the spice-fed animals. This was corroborated by a decreased cholesterol:phospholipid ratio in the jejunal and ileal regions of the intestine. These dietary spices stimulated the activities of BBM enzymes (glycyl-glycine dipeptidase, leucine amino peptidase and $\gamma$-glutamyl transpeptidase) in the jejunal mucosa, suggesting a modulation in membrane dynamics due to the apolar spice bioactive compounds interacting with surrounding lipids and hydrophobic portions in the protein vicinity, which may decrease the tendency of membrane lipids to act as steric constraints to enzyme proteins and thus modify enzyme conformation. Scanning electronic microscopy of the intestinal villi in these spice treatments revealed alterations in the ultrastructure, especially an increase in microvilli length and perimeter which would mean a beneficial increase in the absorptive surface of the small intestine, providing for an increased bioavailability of micronutrients. Thus, dietary spices (black pepper, red pepper and ginger) were evidenced to induce alterations in BBM fluidity and passive permeability property, associated with the induction of an increased microvilli length and perimeter, resulting in an increased absorptive surface of the small intestine.

Dietary spices: Brush-border enzymes: Intestinal brush border: Fluidity

Piperine, the active principle of black and long pepper, is now established as a bioavailability enhancer of various structurally and therapeutically diverse drugs and other phytochemicals $^{(1,2)}$. The potential of piperine to increase the bioavailability of drugs in humans is of great clinical significance. Studies have indicated that piperine is absorbed very quickly across the intestinal barrier. It exhibits passive diffusion with non-saturable absorption kinetics, short absorption clearance and a high permeability coefficient ${ }^{(3)}$. It is, therefore, reasonable to presume that since piperine is an apolar molecule, it may modulate membrane dynamics due to its easy partitioning in the hydrophobic core and so assist the easy permeation of solutes. The available research data point out that piperine increases the bioavailability of drugs either by promoting rapid absorption from the gastrointestinal tract, or by retarding the drug from being metabolised in the liver or by a combination of these two mechanisms.

The effect of piperine, the pungent principle of black pepper, on the absorptive function of the intestine has been studied in in vitro experiments which showed that piperine $(25-100 \mu \mathrm{M})$ significantly stimulated $\gamma$-glutamyl transpeptidase activity, enhanced the uptake of radiolabelled amino acids and increased lipid peroxidation in freshly isolated epithelial cells of rat jejunum ${ }^{(4)}$. The kinetic behaviour of $\gamma$-glutamyl transpeptidase towards substrate and acceptor altered in the presence of piperine. The results suggested that piperine may interact with the lipid environment to produce effects leading to increased permeability of the intestinal cells. It is hypothesised that piperine's bioavailability-enhancing property may be attributed to increased absorption, which may be due to alterations in membrane lipid dynamics and changes in the conformation of enzymes in the intestine ${ }^{(5)}$. Results of membrane fluidity studies using an apolar fluorescent probe, pyrene (which measures the fluid properties of the hydrocarbon core), showed an increase in intestinal brush-border membrane (BBM) fluidity.

Piperine also stimulates leucine amino peptidase and glycyl-glycine dipeptidase activity, due to an alteration in enzyme kinetics ${ }^{(5)}$. This suggests that piperine could modulate membrane dynamics due to its apolar nature by interacting with surrounding lipids and hydrophobic portions in the protein vicinity, which may decrease the tendency of membrane lipids to act as steric constraints to enzyme proteins and thus modify enzyme conformation. Ultrastructural studies with piperine showed an increase in microvilli length with a prominent increase in free ribosomes and ribosomes on the endoplasmic reticulum in enterocytes, suggesting that synthesis or turnover of cytoskeletal components or membrane

Abbreviations: BBM, brush-border membrane; DPH, 1,6-diphenyl-1,3,5-hexatriene; Tris, 2-amino-2-hydroxymethyl-propane-1,3-diol.

* Corresponding author: Dr K. Srinivasan, fax +91821 2517233, email ksri.cftri@gmail.com 
proteins may be involved in the observed effect. Thus, it is suggested that piperine may be inducing alterations in membrane dynamics and permeation characteristics, along with induction of the synthesis of proteins associated with cytoskeletal function, resulting in an increase in the small intestine absorptive surface, thus assisting efficient permeation through the epithelial barrier.

In the context of piperine, the pungent bioactive compound of black pepper, possibly promoting the absorption of other phytochemicals and drugs from the gastrointestinal tract by modulation of the ultrastructure, it is most relevant to examine if other pungent spices such as red pepper or its pungent principle (capsaicin) and ginger also exert similar influences on the ultrastructure and fluidity of the intestinal brush border. In the present investigation, an animal study examined the possible influence of the dietary intake of pungent spices (black pepper, red pepper and ginger) and pungent spice bioactive compounds (piperine and capsaicin) on: (i) membrane fluidity in intestinal BBM using a fluorescent probe, (ii) activity of intestinal enzymes whose activity is dependent on the interaction with the lipid microenvironment of the membrane, and (iii) ultrastructural alterations in the intestinal epithelium.

\section{Experimental methods}

\section{Materials}

Piperine and capsaicin, the active principles of black pepper and red pepper, were procured from Fluka Chemie AG (Buchs, Switzerland). Black pepper, red pepper and ginger were locally purchased and milled to fine powders. All other chemicals used were of analytical grade and were obtained from Sigma Chemical Co. (St Louis, MO, USA). The solvents were distilled before use. ADP, bovine serum album, 1,6diphenyl-1,3,5-hexatriene (DPH), $\gamma$-glutamyl- $p$-nitroanilide, glycyl-glycine, ouabain, 2-amino-2-hydroxymethyl-propane1,3-diol (Tris)-ATP, $\beta$-glycerophospate, tripalmitin, Tris- $\mathrm{HCl}$ and thiobarbituric acid were purchased from Sigma Chemical Co. Triethanolamine, vitamin $\mathrm{E}$ acetate, vitamin A acetate, cholecalciferol and EDTA were obtained from Himedia Laboratories (Mumbai, India). Casein was purchased from Nimesh Corporation (Mumbai, India). Maize starch, cane sugar powder and refined groundnut oil were purchased from a local market. Salt mixture (Bernhardt-Tommarelli modified) was purchased from SISCO Research Laboratories (Mumbai, India).

\section{Animal treatment}

Animal experiments were carried out taking appropriate measures to minimise pain or discomfort in accordance with standard guidelines for the care and use of animals for experimental purposes and with due approval from the Institutional Animal Ethics Committee. Male Wistar rats (ten rats per group) weighing 65-70 $\mathrm{g}$ and housed in individual stainlesssteel cages were maintained on various experimental diets ad libitum for 8 weeks. The basal diet consisted of $(\%)$ : casein, 21; cane sugar, 10; maize starch, 54; National Research Council (NRC) vitamin mixture, 1; Bernhart-Tommarelli modified NRC salt mixture, 4; refined groundnut oil, 10.
The test spices or spice principles were incorporated into this basal diet, replacing an equivalent amount of maize starch to give the various experimental diets containing: black pepper $(0.5 \%)$; red pepper $(3.0 \%)$; ginger $(0.05 \%)$; piperine $(0.02 \%)$; or capsaicin $(0.01 \%)$.

At the end of the feeding trial, overnight fasted rats were killed under diethyl ether anaesthesia. Small intestines consisting of $15 \mathrm{~cm}$ long segments beyond $10 \mathrm{~cm}$ of the pyloric end were quickly excised and were flushed with cold physiological saline. These intestinal segments were everted over a glass rod and the mucosa was scraped off gently with the help of a glass slide. The mucosal scrapings were homogenised $(10 \%)$ in icecold $0 \cdot 2 \mathrm{M}$-phosphate buffer ( $\mathrm{pH} 7.4)$ using a Potter-Elvehjem homogeniser for $2 \mathrm{~min}$ and centrifuged for $10 \mathrm{~min}$ at $3000 \mathrm{~g}$ and the supernatant fractions were used for enzyme activity determinations $^{(5)}$.

\section{Enzyme activities in intestinal mucosa}

Leucine amino peptidase activity in intestinal mucosa was assayed by measuring the amount of $\beta$-naphthylamine released using L-leucyl $\beta$-naphthylamine as substrate by following the rate of increase in absorbance at $340 \mathrm{~nm}$ according to Lee et al. ${ }^{(6)}$. The enzyme activity was expressed as $\mu \mathrm{mol}$ $\beta$-naphthylamine released/min per $\mathrm{mg}$ protein. Glycyl-glycine dipeptidase activity was determined by following the decrease in absorbance at $220 \mathrm{~nm}$ due to the hydrolysis of peptide bonds of glycyl-glycine according to Josefsson \& Lindberg ${ }^{(7)}$. Enzyme activity was expressed as $\mu \mathrm{mol}$ glycyl-glycine hydrolysed/min per mg protein. $\gamma$-Glutamyl transpeptidase $(\gamma$-GT) was assayed according to Indrani \& $\mathrm{Hill}^{(8)}$ by using $\gamma$-glutamyl- $p$-nitroanilide as donor and glycylglycine as acceptor substrates and following the change in absorbance at $405 \mathrm{~nm}$ for $5 \mathrm{~min}$. One unit of enzyme activity is the amount of enzyme that transforms $1 \mu \mathrm{mol}$ substrate per $\min$ at $25^{\circ} \mathrm{C}$ and the activity was expressed as $\mu \mathrm{mol}$ substrate released/min per $\mathrm{mg}$ protein.

$\mathrm{Na}^{+}, \mathrm{K}^{+}$-ATPase activity was assayed according to Vajreshwari et al. ${ }^{(9)}$. The released inorganic phosphate $(\mathrm{Pi})$ by using ATP as substrate was estimated according to the method of Taussky \& Shorr ${ }^{(10)}$. The enzyme activities were expressed as $\mu \mathrm{mol} \mathrm{Pi}$ formed/h per $\mathrm{mg}$ protein. Alkaline phosphatase activity was assayed according to Hubscher \& West ${ }^{(11)}$ by estimating the Pi liberated at $\mathrm{pH} 9.5$ using $\beta$-glycerophosphate as substrate. The enzyme activities were expressed as $\mu \mathrm{mol} \mathrm{Pi}$ formed/h per $\mathrm{mg}$ protein. Protein content was determined using the method of Lowry et al. ${ }^{(12)}$.

\section{Preparation of intestinal brush-border membrane}

Intestinal BBM was isolated following the method of Kessler et al. ${ }^{(13)}$. Freshly excised intestines were flushed with cold physiological saline, everted, and the mucosa was scraped off gently with the help of a glass slide. Then $1 \%$ mucosal homogenate in ice-cold $50 \mathrm{~mm}$-mannitol plus $2 \mathrm{~mm}-$ Tris- $\mathrm{HCl}$ buffer ( $\mathrm{pH} 7 \cdot 1$ ) was prepared, and filtered through $40 \mu \mathrm{m}$ pore size nylon. To the filtrate, anhydrous $\mathrm{CaCl}_{2}$ was added with constant stirring on a magnetic stirrer to a final concentration of $10 \mathrm{mM}$. After $15 \mathrm{~min}$, it was centrifuged at $2000 \mathrm{~g}$, for $10 \mathrm{~min}$ at $4^{\circ} \mathrm{C}$. The supernatant fraction was re-centrifuged at $27000 \mathrm{~g}$ for $30 \mathrm{~min}$. The pellet was 
suspended in $2 \mathrm{ml}$ of $50 \mathrm{~mm}$-mannitol in $10 \mathrm{~mm}$-Tris buffer (pH 7.5) and re-centrifuged at $27000 \mathrm{~g}$ for $30 \mathrm{~min}$. The final pellet was re-suspended in $50 \mathrm{~mm}$-buffer.

\section{Membrane fluidity studies}

Fluidity of the BBM was measured according to the method described by Livshin et al. ${ }^{(14)}$. A lipid-soluble fluoro probe (DPH) dissolved in tetrahydrofuran (final concentration of $1 \mu \mathrm{M})$ was mixed with BBM preparations $(0.4 \mathrm{mg}$ protein $/ \mathrm{ml})$ in stabilising buffer ( $50 \mathrm{~mm}$-mannitol; 2 mM-Tris- $\mathrm{HCl}$; $\mathrm{pH} 7 \cdot 1$ ) with vigorous agitation and incubated at $25^{\circ} \mathrm{C}$ for $30 \mathrm{~min}$. Steady-state fluorescence polarisation was recorded in a Hitachi F-4000 spectrophotometer (Hitachi, Tokyo, Japan), operated in the ratio mode with $5 \mathrm{~nm}$ excitation and emission band pass with $355 \mathrm{~nm}$ excitation and $430 \mathrm{~nm}$ emission wavelengths. The polarisation of the fluorescence was expressed in terms of the fluorescence anisotropy ' $r$ ', and calculated according to:

$$
\mathrm{r}=\left(\mathrm{I}_{\mathrm{vv}}-\mathrm{I}_{\mathrm{vH}} \times \mathrm{G}\right) /\left(\mathrm{I}_{\mathrm{vv}}+\mathrm{I}_{\mathrm{vH}} \times \mathrm{G}\right),
$$

where $I_{v v}$ and $I_{v H}$ are the components of emitted light intensity, parallel and perpendicular respectively, with reference to the direction of polarisation of the excitation light, and $G$ is the correction factor $\left(\mathrm{G}=\mathrm{I}_{\mathrm{vv}} / \mathrm{I}_{\mathrm{vH}}\right)$ used to correct for unequal transmission in the optics. The anisotropy parameter, $\left(\left(\mathrm{r}_{0} / \mathrm{r}\right)-1\right)^{-1}$, was calculated with the limiting anisotropy value of DPH of $r_{0}=0.362$.

\section{Membrane cholesterol and phospholipids}

Total lipids were extracted from the intestinal brush border by the method of Folch et al. ${ }^{(15)}$. Cholesterol was estimated by the method of Searcy \& Bergquist ${ }^{(16)}$. Phospholipids were quantified by the ferrous ammonium thiocyanate method using dipalmitoyl phosphatidylcholine as the standard ${ }^{(17)}$.

\section{Scanning electron microscopic studies}

From the freshly excised intestines, small pieces of jejunum $(15 \mathrm{~cm}$ beyond $10 \mathrm{~cm}$ of the pyloric end) from control and spice-treated rats were processed for electron microscopy. Scanning electron microscopic studies of the intestinal brush border were done according to Daddow ${ }^{(18)}$. Intestinal sections were fixed by incubating in $1 \%$ glutaraldehyde in 0.1 M-phosphate buffer ( $\mathrm{pH} \mathrm{7.4)}$ for $3 \mathrm{~h}$ on ice with regular mixing and then thoroughly washed with water and dehydrated by stepwise washing with increasing concentrations of acetone (from 30 to $95 \%$ ). Dehydrated samples were gold coated by spattering and then examined under the scanning electron microscope (LEO 435VP; Leo Electron Microscopy Ltd, Cambridge, Cambs, UK) at different magnifications. The ultrastructure of the intestinal brush border was examined with particular reference to microvilli length and perimeter.

\section{Light microscopic studies}

From the freshly excised small intestine, small pieces of jejunum (spanning $15 \mathrm{~cm}$ beyond $10 \mathrm{~cm}$ of the pyloric end) were also processed for light microscopic studies by immediately fixing in $10 \%$ formalin solution. These were processed further using alcohol, acetone and benzene. After paraffin infiltration, blocks were made. Sections of $5 \mu \mathrm{m}$ thickness were cut and stained with haematoxylin and eosin. These were observed through a light microscope (Leitz Laborlux POL, Wetzlar, Germany). Intestinal microvilli height and perimeter were measured using an ocular micrometer (Erma, Tokyo, Japan).

\section{Statistical analysis}

Results are expressed as mean values with their standard errors and comparisons between groups were made by means of one-way ANOVA ${ }^{(19)}$. Comparisons among different groups were made by applying Dunnett's test. Differences were considered significant when $P<0 \cdot 05$.

\section{Results}

Effect of dietary spices on activities of enzymes associated with small-intestinal brush border

All the dietary spices, namely, black pepper, piperine, red pepper, capsaicin and ginger, stimulated the activities of glycyl-glycine dipeptidase, leucine aminopeptidase, $\gamma$-glutamyl transpeptidase and alkaline phophatase in the small-intestinal

Table 1. Influence of dietary spices on the activities of small-intestinal brush-border enzymes

(Mean values with their standard errors for eight animals per group)

\begin{tabular}{|c|c|c|c|c|c|c|c|c|}
\hline \multirow[b]{2}{*}{ Diet group } & \multicolumn{2}{|c|}{$\begin{array}{l}\text { Glycyl-glycine } \\
\text { dipeptidase } \\
\text { (mg dipeptide } \\
\text { hydrolysed/min } \\
\text { per mg protein) }\end{array}$} & \multicolumn{2}{|c|}{$\begin{array}{l}\text { Leucine amino } \\
\text { peptidase } \\
\text { ( } \mu \text { mol } \beta \text {-napthyl } \\
\text { amine released/min } \\
\text { per mg protein) }\end{array}$} & \multicolumn{2}{|c|}{$\begin{array}{c}\gamma \text {-Glutamyl } \\
\text { transpeptidase } \\
\text { ( } \mu \text { mol } p \text {-nitro anilide } \\
\text { released/min per } \\
\text { mg protein) }\end{array}$} & \multicolumn{2}{|c|}{$\begin{array}{c}\text { Alkaline } \\
\text { phosphatase } \\
\text { (mg Pi liberated/h } \\
\text { per mg protein) }\end{array}$} \\
\hline & Mean & SE & Mean & SE & Mean & SE & Mean & SE \\
\hline Control & 31.0 & 0.7 & $48 \cdot 1$ & 1.9 & 0.20 & 0.04 & 0.20 & 0.02 \\
\hline Black pepper & $50 \cdot 0^{*}$ & 2.9 & $65 \cdot 2^{*}$ & 6.5 & ND & & $0.31^{*}$ & 0.02 \\
\hline Piperine & $50 \cdot 4^{\star}$ & 3.4 & $72 \cdot 0^{\star}$ & 3.9 & $0.54^{*}$ & 0.04 & $0.40^{\star}$ & 0.03 \\
\hline Red pepper & $46 \cdot 0^{*}$ & 1.5 & $78 \cdot 8^{\star}$ & $9 \cdot 2$ & ND & & $0.32^{*}$ & 0.01 \\
\hline Capsaicin & $44 \cdot 1^{*}$ & 1.5 & $68 \cdot 7^{\star}$ & 3.9 & $0.41^{*}$ & 0.03 & $0.35^{\star}$ & 0.02 \\
\hline Ginger & $41 \cdot 0^{*}$ & 2.7 & $62 \cdot 8^{*}$ & $2 \cdot 6$ & $0.54^{*}$ & 0.04 & $0 \cdot 24^{*}$ & 0.01 \\
\hline
\end{tabular}

Pi, inorganic phosphate; ND, not determined.

* Mean value was significantly higher than that of the control group $(P<0.05)$. 
Table 2. Influence of dietary spices on intestinal brush-border $\mathrm{Na}^{+}, \mathrm{K}^{+}$-ATPase ( $\mathrm{mg}$ inorganic phosphate liberated/h per $\mathrm{mg}$ protein) (Mean values with their standard errors for eight animals per group)

\begin{tabular}{|c|c|c|c|c|c|c|c|c|}
\hline \multirow[b]{2}{*}{ Diet group } & \multicolumn{2}{|c|}{$\begin{array}{l}\text { Ouabain sensitive } \\
\text { (specific activity) }\end{array}$} & \multicolumn{2}{|c|}{$\begin{array}{l}\text { Ouabain insensitive } \\
\text { (specific activity) }\end{array}$} & \multicolumn{2}{|c|}{$\begin{array}{c}\text { Total } \\
\text { (specific activity) }\end{array}$} & \multicolumn{2}{|c|}{$\begin{array}{l}\text { Ouabain sensitive } \\
\text { (\% of total activity) }\end{array}$} \\
\hline & Mean & SE & Mean & SE & Mean & SE & Mean & SE \\
\hline Control & 0.081 & 0.002 & 0.635 & 0.038 & 0.714 & 0.036 & $11 \cdot 8$ & 1.6 \\
\hline Black pepper & $0.171^{*}$ & 0.009 & $0.256 \dagger$ & 0.009 & $0.425 \dagger$ & 0.009 & $45 \cdot 0$ & $4 \cdot 1$ \\
\hline Piperine & $0.123^{\star}$ & 0.008 & $0.426 \dagger$ & 0.026 & $0.552 \dagger$ & 0.031 & 22.5 & $2 \cdot 0$ \\
\hline Red pepper & $0.158^{*}$ & 0.011 & $0.307 \dagger$ & 0.015 & $0.466 \dagger$ & 0.009 & $37 \cdot 7$ & $3 \cdot 6$ \\
\hline Capsaicin & $0.123^{\star}$ & 0.009 & $0.417 \dagger$ & 0.024 & $0.582 \dagger$ & 0.026 & 18.9 & 2.4 \\
\hline Ginger & $0.111^{*}$ & 0.006 & $0.384 \dagger$ & 0.016 & $0.493 \dagger$ & 0.032 & 21.6 & 1.8 \\
\hline
\end{tabular}

${ }^{*}$ Mean value was significantly higher than that of the control group $(P<0.05)$.

† Mean value was significantly lower than that of the control group $(P<0.05)$.

mucosa (Table 1). The activity of intestinal glycyl-glycine dipeptidase was significantly higher than that of the control group in all the test spice groups (32-62\% increase), with the highest increase found in black pepper and piperine groups. The activity of intestinal leucine amino peptidase was similarly increased by $30-64 \%$ by all the tested dietary spices. Dietary red pepper produced the highest stimulation of this enzyme activity $(64 \%)$ followed by piperine $(50 \%)$. The activity of intestinal $\gamma$-glutamyl transpeptidase was also significantly higher than that of the control group in all the test spice groups (106-169\% increase). The increase in the enzyme activity was as high as $169 \%$ as a result of piperine and ginger feeding. Dietary black pepper, piperine, red pepper, capsaicin and ginger effectively increased intestinal alkaline phosphatase $(20-100 \%)$, with piperine producing the maximum increase of $100 \%$.

Dietary black pepper, piperine, red pepper, capsaicin and ginger significantly stimulated the activities of intestinal ouabain-sensitive $\mathrm{Na}^{+}, \mathrm{K}^{+}$-ATPase (Table 2). The extent of stimulation in the activity of ouabain-sensitive $\mathrm{Na}^{+}$, $\mathrm{K}^{+}$-ATPase produced by dietary black pepper and red pepper was 111 and $95 \%$, respectively. Both piperine and capsaicin produced a similar increase of $52 \%$ in the enzyme activity. Total $\mathrm{Na}^{+}, \mathrm{K}^{+}$-ATPase activity as well as the ouabain-insensitive fraction of $\mathrm{Na}^{+}, \mathrm{K}^{+}$-ATPase activity were lowered by all the test spices (Table 2). As a result of increasing the ouabain-insensitive portion of $\mathrm{Na}^{+}$, $\mathrm{K}^{+}$-ATPase, the percentage portion of ouabain-sensitive $\mathrm{Na}^{+}, \mathrm{K}^{+}$-ATPase in the total $\mathrm{Na}^{+}, \mathrm{K}^{+}$-ATPase was significantly higher in all the spice treatments.

\section{Effect of dietary spices on the fluidity of intestinal brush-border membrane}

The effects of dietary spices on fluorescence anisotropy ' $r$ ' in microvillus membranes prepared from identical segments of the duodenum, jejunum and ileum of each group assessed with the lipid-soluble fluoroprobe DPH are illustrated in Table 3. Since there exists an inverse relationship between lipid fluidity and anisotropy parameter, lipid fluidity, as assessed by the fluorescence anisotropy of DPH, was significantly higher in spice-treated rats. Piperine produced 104 and $51 \%$, and capsaicin produced 72 and $108 \%$ increases in fluidity in the ileum and jejunum, respectively, and ginger produced 49 and $25 \%$ increases in fluidity in the ileum and jejunum, respectively. In the case of the duodenum, piperine and capsaicin produced decreases of 22 and $44 \%$ in fluidity, while ginger had no effect on the same.

\section{Effect of dietary spices on intestinal membrane lipid composition}

Intestinal membrane lipid composition was examined in order to determine the factors responsible for the foregoing differences in membrane fluidity. Cholesterol concentration was significantly lower in the villi of the jejunum portion in all the three spice-treated groups when compared with control animals (Table 4). Cholesterol concentration was also significantly lower in the villi of the ileum portion in capsaicin- and ginger-treated groups when compared with control animals. The cholesterol concentration of the duodenum portion of

Table 3. Effect of dietary spices on intestinal brush-border membrane fluidity (Mean values with their standard errors for eight animals per group)

\begin{tabular}{|c|c|c|c|c|c|c|c|c|c|c|c|c|}
\hline \multirow[b]{3}{*}{ Diet group } & \multicolumn{6}{|c|}{ Anisotropy $\left(\mathrm{r}_{\mathrm{DPH}}\right)$} & \multicolumn{6}{|c|}{ Anisotropy parameter $\left(\left(r_{0} / r\right)-1\right)^{-1}$} \\
\hline & \multicolumn{2}{|c|}{ Duodenum } & \multicolumn{2}{|c|}{ Jejunum } & \multicolumn{2}{|c|}{ Ileum } & \multicolumn{2}{|c|}{ Duodenum } & \multicolumn{2}{|c|}{ Jejunum } & \multicolumn{2}{|c|}{ Ileum } \\
\hline & Mean & SE & Mean & SE & Mean & SE & Mean & SE & Mean & SE & Mean & SE \\
\hline Control & 0.134 & 0.003 & 0.218 & 0.010 & 0.228 & 0.021 & 0.587 & 0.026 & 1.550 & 0.094 & 1.955 & 0.166 \\
\hline Piperine & 0.153 & 0.021 & $0 \cdot 183^{\star}$ & 0.010 & $0.172^{*}$ & 0.020 & $0.756^{*}$ & 0.074 & $1.030^{\star}$ & 0.084 & $0.960^{*}$ & 0.201 \\
\hline Capsaicin & 0.156 & 0.015 & $0 \cdot 154^{*}$ & 0.004 & $0 \cdot 188^{*}$ & 0.012 & $0.758^{*}$ & 0.026 & $0 \cdot 745^{\star}$ & 0.040 & $1 \cdot 137^{*}$ & 0.154 \\
\hline Ginger & 0.132 & 0.002 & $0 \cdot 189^{*}$ & 0.010 & $0 \cdot 182^{*}$ & 0.010 & 0.573 & 0.012 & $1 \cdot 243^{*}$ & 0.059 & $1 \cdot 315^{\star}$ & 0.175 \\
\hline
\end{tabular}


the intestine remained unaffected by the spice treatments. The phospholipid content of the villi of the duodenum and jejunum portions was significantly higher in capsaicin-fed animals when compared with control animals. Dietary piperine or ginger had no influence on the phospholipid content of the intestinal villi.

A significant decrease in cholesterol in the test spice groups, both in the jejunum and ileum segments, with or without an increase in the phospholipid content, resulted in a relatively lower cholesterol:phospholipid ratio. The cholesterol:phospholipid ratio was significantly lower in the villi of the jejunum and ileum portions of all the three test spice groups as compared with the control group in the respective part of the small intestine (Table 4). The jejunum of the capsaicin-treated group showed a $30.2 \%$ decrease in the cholesterol:phospholipid ratio, followed by piperine $(19.3 \%)$ and ginger $(18.2 \%)$. Similarly, the ileum of the capsaicin-treated group showed a $17.7 \%$ decrease in the cholesterol:phospholipid ratio, followed by ginger $(12.2 \%)$ and piperine $(9.8 \%)$. The ratio of cholesterol:phospholipid remained unchanged in the duodenum as a result of the spice treatments. All these changes effected by dietary spices in the villi lipid profile are expected to increase the lipid fluidity of the membranes of the jejunum and ileum. These lipid compositional changes are concordant with the enhanced fluidity of the membranes (jejunum and ileum) as assessed by fluorescence anisotropy using the fluorescent probe DPH.

\section{Effect of dietary spices on the ultrastructure of intestinal epithelium}

Electron micrographs of control and spice-treated rat jejunum recorded at $\times 29000$ magnification displayed regular and well-formed microvilli (Fig. 1). All the three spice treatments generally induced an increase in microvilli length (Figs. 2 and 3). Among the test spices, capsaicin produced the maximum

(a)

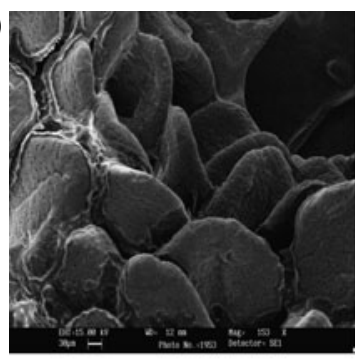

(c)

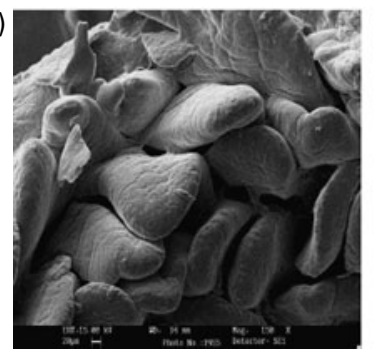

(b)

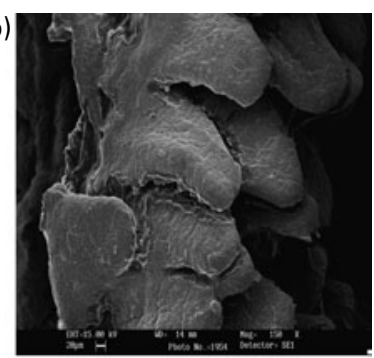

(d)

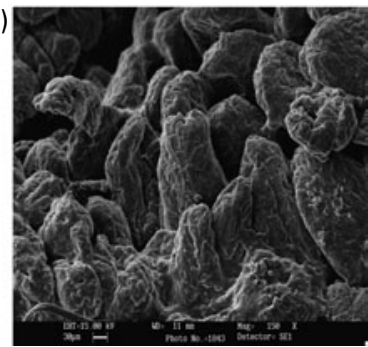

Fig. 1. Scanning electron microscopic photographs of intestinal cross sections showing enlarged microvilli in spice-treated animal groups $(\times 150)$. (a) Control; (b) piperine; (c) capsaicin; (d) ginger. 
(a)

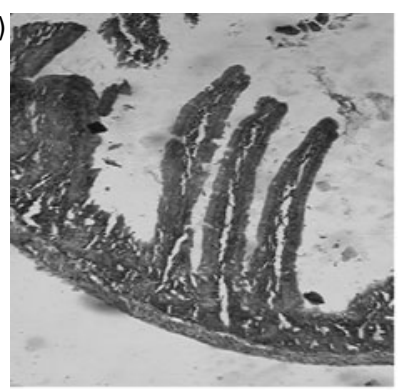

(d)

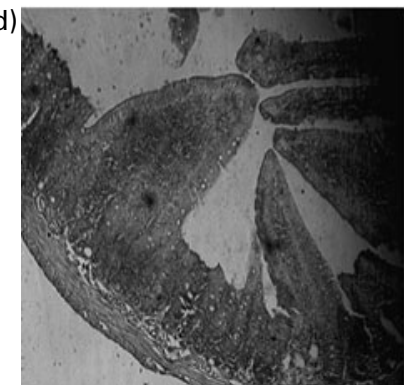

(b)

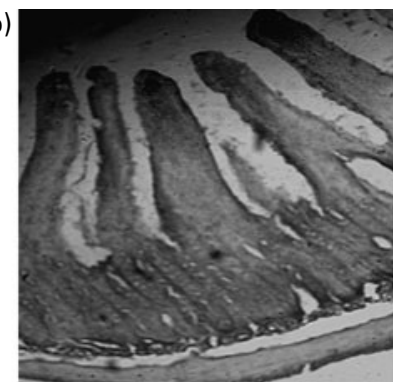

(e)

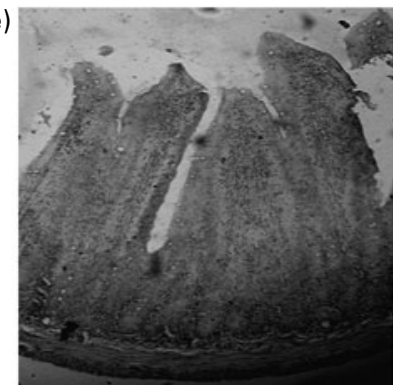

(c)
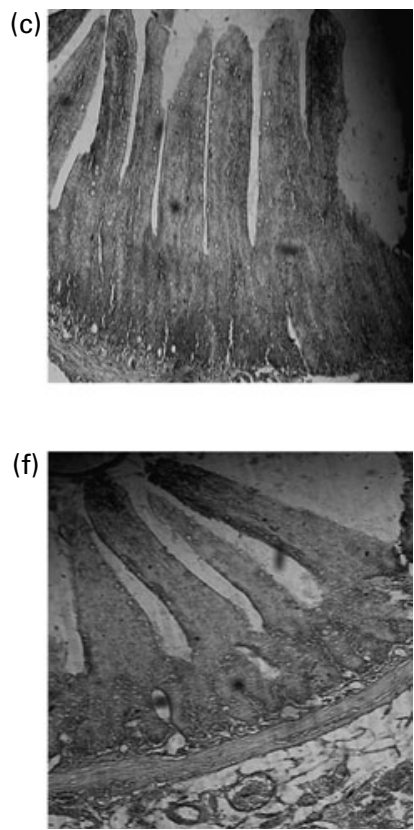

Fig. 2. Light microscopic photographs of intestinal cross sections showing enlarged microvilli in spice-treated animal groups (haematoxylin-eosin $\times 100$ ). (a) Control; (b) black pepper; (c) piperine; (d) red pepper; (e) capsaicin; (f) ginger.

increase of $33 \%$, followed by piperine and ginger (10\%) (Fig. 3). A prominent increase in the perimeter of the villi was also observed. Among the test spices, capsaicin produced the maximum increase $(29 \%)$, followed by ginger $(14 \%)$ and piperine (12\%) (Fig. 3).

\section{Discussion}

Compounds with high lipid solubility cause changes in membrane dynamics because of easy partitioning in a lipid matrix. The lipophilic compounds are capable of entering the hydrophobic region of both lipids and proteins in the membrane core $^{(20)}$. Permeability barriers in enterocytes are represented by different transport enzymes in the $\mathrm{BBM}^{(21)}$ and any alteration in the membrane may affect its permeability characteristics and activity ${ }^{(22)}$.

The BBM is the site of digestive and transport processes of the small intestine and there is considerable evidence that many of its protein-mediated functions are influenced by the composition and physical state of its lipids ${ }^{(23)}$. Glycyl-glycine dipeptidase and leucine amino peptidase are important hydrolysing enzymes of the intestinal BBM, located on the external surface of the $\mathrm{BBM}^{(24)}$, whose activity is dependent on interaction with the lipid microenvironment of the membrane. They consist of a hydrophilic part (catalytic) protruding to the external surface and hydrophobic part embedded within the bilayer, important for maintaining optimal conformation of the enzyme ${ }^{(25,26)}$. The present studies have shown that dietary spices caused enhancements in glycyl-glycine dipeptidase, leucine amino peptidase and $\gamma$-glutamyl transpeptidase activity in the jejunal mucosa. Increased activities of intestinal enzymes suggest that pungent spices could modulate membrane dynamics due to their apolar nature by interacting with surrounding lipids and hydrophobic portions in the protein vicinity, which may decrease the tendency of membrane lipids to act as steric constraints to enzyme proteins and thus modify enzyme conformation. This is also evident in the fluidity effect of tested spices or spice compounds on the membrane lipids. Thus, it is suggested that these dietary spices may be inducing alterations in membrane fluidity and passive permeability properties which results in the possible increased absorption of micronutrients from the small intestine.

Membrane fluidity studies using an apolar fluorescent probe, diphenyl hexatriene (which measures the fluid properties of the hydrocarbon core), showed an increase in intestinal BBM fluidity. The BBM is rich in many enzymes and transport proteins. Enzyme activity and certain transmembrane

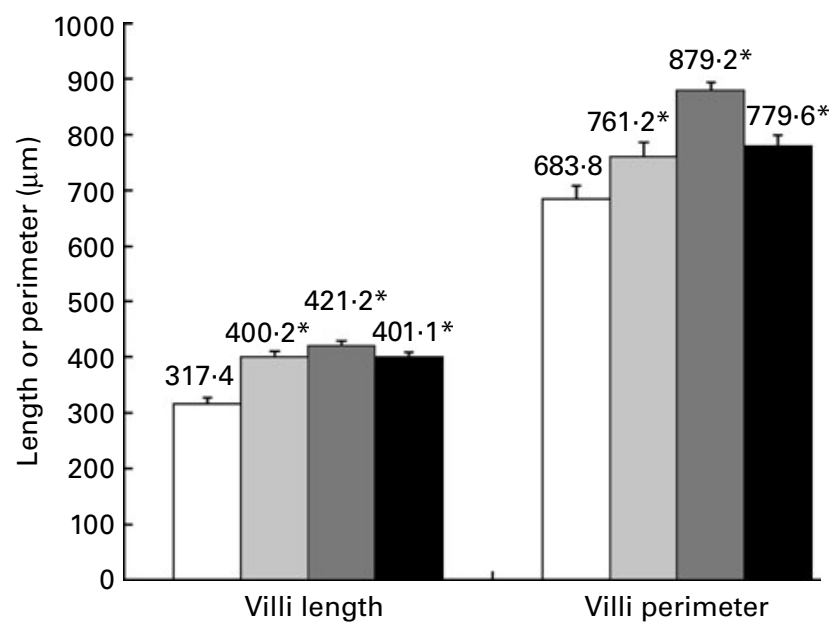

Fig. 3. Effect of dietary spices on intestinal microvilli length and perimeter. $(\square)$, Control; ( $\square$ ), piperine; ( $\square$ ), capsaicin; $(\square)$, ginger. Values are means of 100 microvilli per group, with standard errors represented by vertical bars. ${ }^{*}$ Mean value was significantly higher than that of the control group $(P<0.05)$. 
transport processes could be influenced by the physical state and lipid composition of the membranes. It is widely accepted that membrane functions are regulated by membrane fluidity $^{(27-30)}$. An increase in membrane disorder has been shown to contribute to the enhanced absorption of various drugs, for example, salicylates in epithelial and cancer cells ${ }^{(31,32)}$.

The effect of test spices on membrane fluidity may therefore be attributable to their easy partitioning in the membrane (due to the apolar nature of spice compounds) and the configuration that they assume with neighbouring molecules in the membrane, resulting in altered lipid dynamics. An inverse relationship exists between membrane lipid fluidity and the anisotropy parameter ${ }^{(33)}$. The fluorescence anisotropy of this probe in bilayer membranes is determined mainly by the maximal hindered anisotropy and provides an estimate of the static component of 'fluidity', i.e. of lipid order ${ }^{(34)}$. Because DPH partitions equally between gel and liquid crystal domains of membranes, its anisotropy gives a submicroscopical view of the overall membrane lipid order ${ }^{(35)}$. This submicroscopic parameter is believed to be relevant for most physiological functions related to fluidity. Determinations of the fluorescence, which gives access to the rotational diffusion properties of the probe, have confirmed that DPH steady-state anisotropy measurements report essentially on the lipid order in membranes ${ }^{(36)}$.

Epithelial cells exhibit a marked morphological polarity and their vectorial transport function is achieved through a polarised distribution of transport systems between the apical and basolateral domains of the plasma membrane. Modifications of membrane fluidity are well recognised to affect the passive permeability properties of membranes ${ }^{(37,38)}$. The concept of control of membrane functions by lipid physical state supposes that fluidity (and/or composition) affects the activity of numerous proteins. This effect can result from a direct action on the conformation or on the conformational changes required by the function of a given protein or may involve the ease of proteins to associate or dissociate ${ }^{(27)}$. It has been established that freedom of protein conformational changes can be regulated by lipid fluidity ${ }^{(39)}$.

The term lipid fluidity may refer to the relative motional freedom of the lipid molecules in the membrane lipid bilayer $^{(40)}$, which include translational (or lateral) diffusion as well as rotational movement of the fatty acid tail of the phospholipids and sphingolipids. Lateral diffusion was measured by the excimer formation of the probe DPH that demonstrated an increased membrane fluidity in piperine-, capsaicin- and ginger-treated animals. This might have resulted due to the partial lipid removal and more motional freedom of the probe in the hydrocarbon phase.

A wide variety of substances such as glucose and amino acids are carried across the intestine through the ingested diet. Thus, any alteration in the biochemical or biophysical composition of the small intestine by dietary spices may affect its functional and dynamic aspect. In the present study, a significant increase in the intestinal brush-border enzymes (leucine aminopeptidase, glycyl-glycine dipeptidase, $\gamma$-glutamyl transpeptidase, ouabain-sensitive $\mathrm{Na}^{+}, \mathrm{K}^{+}$-ATPase and alkaline phosphatase) was noticed in the animals treated with all the tested pungent spices or their active principles. These increased activities of BBM enzymes can be due to a rise in the number of molecular enzyme proteins.
It has long been suggested that $\mathrm{Na}^{+}, \mathrm{K}^{+}$-ATPase activity in the $\mathrm{BBM}$ is dependent on the physical state of the membrane ${ }^{(41)}$. The findings that purified $\mathrm{Na}^{+}, \mathrm{K}^{+}$-ATPase is associated with about 240 molecules of phospholipids including the sixty molecules constitutive of the lipid annulus, and that irreversible loss in activity occurred upon delipidation of the enzyme, strengthened the view of the lipid dependence of its activity $^{(42)}$. Decreasing the membrane fluidity of bovine kidney basolateral membranes by increasing their cholesterol content in vitro markedly inhibits $\mathrm{Na}^{+}, \mathrm{K}^{+}$-ATPase activity ${ }^{(43)}$. Lipid sensitivity of conformational changes associated with $\mathrm{Na}^{+}, \mathrm{K}^{+}$-ATPase activity was also confirmed by experiments under high hydrostatic pressure ${ }^{(44)}$. It has been reported that in intestinal basolateral membranes, methylation is associated with an increase in membrane fluidity and $\mathrm{Na}^{+}, \mathrm{K}^{+}$-ATPase activity $^{(45)}$. The present study has also evidenced increased activity of ouabain-sensitive ATPase along with increased fluidity of the BBM as a result of dietary spice treatment.

Cholesterol is a major constituent of the plasma membranes, and changes in the cholesterol content of biological membranes alter the fluidity of the lipid bilayer and concurrently influence a variety of plasma membrane functions including enzyme activities and ion transport processes ${ }^{(36)}$. The role of in vivo and in vitro alterations in cell membrane cholesterol content and/or fluidity in the modulation of $\mathrm{Na}^{+}, \mathrm{K}^{+}$-ATPase activity has been well studied ${ }^{(46)}$. The present data on the concurrent changes in the fluidity of the BBM, cholesterol: phospholipid ratio and the activity of ouabain-sensitive $\mathrm{Na}^{+}, \mathrm{K}^{+}$-ATPase in response to dietary treatments with piperine, capsaicin and ginger are in agreement with this earlier report.

Changes in microvillus membrane lipid fluidity estimated by fluorescence polarisation spectrometry directly paralleled the changes in the cholesterol:phospholipid ratio. In the case of the jejunum and ileum, membrane fluidity was increased and also the cholesterol:phospholipid ratio was considerably decreased in rats treated with test spices compared with the control group. Thus, the observed difference in BBM fluidity in the spice-fed animals may have resulted in part from differences in the cholesterol:phospholipid ratio.

Further, the tested dietary spices produced interesting changes in the ultrastructure of the intestinal epithelium. Scanning electronic microscopic examination of the intestinal villi in animals fed spices or spice principles revealed alterations in the ultrastructure, especially an increase in microvilli length and also perimeter. This would mean an increase in the absorptive surface area of the small intestine that may contribute to an increase in the absorption of micronutrients. Such an increased villi surface as a result of dietary spices suggests that synthesis or turnover of cytoskeletal components or membrane proteins may be involved in the observed effect. It has been suggested that the brush-border cytoskeleton is responsible for the shape, stability and motility of microvilli composed mainly of actin, myosin and filament-binding proteins ${ }^{(47)}$. Very little is known about the mechanism that regulates microvilli length. Some researchers have reported that chemicals such as cycloheximide ${ }^{(48)}$ and colchicines ${ }^{(49)}$, as well as $\operatorname{diet}^{(50)}$, affect the topography of microvilli. It could be that synthesis and turnover of cytoskeletal components are involved in the increased microvilli length and perimeter by dietary spices. 
The present animal study thus suggests that all the three pungent dietary spices (black pepper, red pepper and ginger) modulate BBM dynamics due to solubility characteristics of their bioactive compounds (piperine, capsaicin, and possibly 6-gingerol, respectively), by interacting or associating with lipids and hydrophobic portions in the protein vicinity. These effects may decrease the tendency of membrane lipids to act as steric constraints to enzyme proteins and modify enzyme conformation. These effects also induce an increase in microvilli length and perimeter, resulting in a beneficial increase in the absorptive surface of the small intestine, providing for an increased bioavailability of micronutrients. In conclusion, these dietary spices induce alteration in membrane dynamics (increased membrane fluidity) associated with increased microvilli length and perimeter, resulting in an increased absorptive surface of the small intestine. Such a modulation in the ultrastructure of the small intestine is likely to promote the permeation of nutrients through the epithelial barrier. The actual beneficial effect of these specific dietary spices in terms of increasing the absorption of micronutrients such as trace minerals and $\beta$-carotene needs to be evaluated in suitable animal models.

\section{Acknowledgements}

U. N. S. P. is thankful to the Indian Council of Medical Research, New Delhi for the award of a Senior Research Fellowship. The authors are thankful to Dr Sridevi A.Singh, scientist in this Institute, for help in the determination of anisotropy parameters.

U. N. S. P. was responsible for the bench work. K. S. supervised the whole animal experiment and analytical work. K. S. was also the project leader, who handled research planning, data interpretation and writing of the manuscript.

There are no conflicts of interest whatsoever among the authors.

\section{References}

1. Zutshi RK, Singh R, Zutshi U, et al. (1985) Influence of piperine on rifampicin blood levels in patients of pulmonary tuberculosis. J Assoc Physicians India 33, 223-224.

2. Bano G, Raina RK, Zutshi U, et al. (1991) The effect of piperine on bioavailability and pharmacokinetics of propanolol and theophylline in healthy volunteers. Eur J Clin Pharmacol 41, 615-618.

3. Khajuria A, Zutshi U \& Bedi KL (1998) Permeability characteristics of piperine on oral absorption - an active alkaloid from peppers and a bioavailability enhancer. Indian J Exp Biol 36, $46-50$.

4. Johri RK, Thusu N, Khajuria A, et al. (1992) Piperine-mediated changes in the permeability of rat intestinal epithelial cells: status of $\gamma$-glutamyl transpeptidase activity, uptake of amino acids and lipid peroxidation. Biochem Pharmacol 43, $1401-1407$.

5. Khajuria A, Thusu N \& Zutshi U (2002) Piperine modulates permeability characteristics of intestine by inducing alterations in membrane dynamics: influence on brush border membrane fluidity, ultra structure and enzyme kinetics. Phytomedicine $\mathbf{9}$, 224-231.

6. Lee HJ, Larve NJ \& Wilson BI (1971) A simple spectrophotometric assay for amino acyl arylamindases (naphthylamidases), aminopeptidases. Anal Biochem 41, 397-401.
7. Josefsson L \& Lindberg T (1965) Intestinal dipeptides. Spectrophotometric determination and characterization of dipeptidase activity in pig intestinal mucosa. Biochim Biophys Acta 105, 149-161.

8. Indrani N \& Hill PG (1977) Partial purification and some properties of $\gamma$-glutamyl transpeptidase from human bile. Biochim Biophys Acta 483, 57-62.

9. Vajreshwari A, Srinivasa Rao P, Kaplay SS, et al. (1983) Erythrocyte membrane in rats fed high erucic acid containing mustard oil: osmotic fragility and lipid composition and $\mathrm{Na}^{+}, \mathrm{K}^{+}$-and $\mathrm{Ca}^{++}, \mathrm{Mg}^{++}$-ATPases. Biochem Med 29, 74-84.

10. Taussky HH \& Shorr E (1953) A microcolorimetric method for the determination of inorganic phosphorus. J Biol Chem 202, 675-685.

11. Hubscher C \& West GR (1965) Specific assays of some phosphatases in subcellular fractions of small intestinal mucosa. Nature 205, 799-800.

12. Lowry OH, Rosebrough NJ, Farr AL, et al. (1951) Protein measurements with Folin phenol reagent. J Biol Chem 193, 265-275.

13. Kessler M, Acuto O, Storelli C, et al. (1978) A modified procedure for the rapid precipitation of efficiency transporting vesicles from small intestine brush border membrane. Biochim Biophys Acta 506, 136-154.

14. Livshin L, Mokady S \& Cogan U (1987) Protein malnutrition and the function and fluidity of the intestinal microvillus membrane in growing rats. $J$ Nutr 117, 684-688.

15. Folch J, Lees M \& Sloane Stanley GH (1957) A simple method for the isolation and purification of total lipides from animal tissues. J Biol Chem 226, 497-509.

16. Searcy RL \& Bergquist LM (1960) A new color reaction for the quantitation of serum cholesterol. Clin Chim Acta 5, 192-197.

17. Stewart CJM (1980) Colorimetric determination of phospholipids with ammonium ferrothiocyanate. Anal Biochem 104, $10-14$.

18. Daddow LY (1983) A double lead stain method for enhancing contrast of ultra thin sections in electron microscopy, a modified multiple staining technique. J Microscopy 129, 147-153.

19. Dowdy S \& Weardew S (1983) Statistics for Research. New York: John Wiley and Sons.

20. Goldstein DB (1984) The effect of drugs on membrane fluidity. Annu Rev Pharmacol Toxicol 24, 43-64.

21. Esposito G (1984) Polarity of intestinal epithelial cell: permeability of brush border and basolateral membranes. In Pharmacology of Intestinal Permeation, pp. 283-308 [TZ Csaky, editor]. Berlin: Springer-Verlag.

22. Le Grimellec C, Friedlander G, Yanddouziel HE, et al. (1991) Membrane fluidity and transport properties in epithelia. Kidney Int 42, 825-836.

23. Schachter D (1985) Lipid dynamics and lipid-protein interactions in intestinal plasma membranes. In Progress in LipidProtein Interactions, pp. 231-258 [A Watts and JJHHM De Point, editors]. Amsterdam: Elsevier.

24. McDonald JK \& Barrette AJ (1986) Leucyl aminopeptidase. In Mammalian Proteinases. A Glossary and Bibliography, pp. 23-100 [JK McDonald and AJ Barrette, editors]. London: Academic Press.

25. Desnuelle P (1979) Intestinal and renal aminopeptidase: a model of a transmembrane protein. Eur J Biochem 101, 1-11.

26. Ugolev AM, Mityushova NM, Egorova VV, et al. (1979) Catalytic and regulatory properties of the triton and trypsin forms of brush border hydrolases. Gut 20, 737-742.

27. Shinitzy M (1984) Membrane fluidity and cellular functions. In Physiology of Membrane Fluidity, vol. 1, pp. 1-51 [M Shinitzky, editor]. Boca Raton, FL: CRC Press. 
28. Proulx P (1991) Structure-function relationships in intestinal brush border membranes. Biochim Biophys Acta 1071, 255-271.

29. Singer SJ (1992) The structure and function of membranes personal memoir. J Membr Biol 129, 3-12.

30. Gupta PD \& Waheed AA (1992) Effect of starvation on glucose transport and membrane fluidity in rat intestinal epithelial cells. FEBS Lett 300, 263-267.

31. Kaji H, Horie T, Hayashi M, et al. (1985) Fluorescence study on the interaction of salicylate with rat small intestinal epithelial cells: possible mechanism for the promoting effect of salicylate on drug absorption in vivo. Life Sci 37, 523-530.

32. Pacilio C, Florio S, Pagnini U, et al. (1998) Modification of membrane fluidity and depolarization by some anthracyclines in different cell lines. Anticancer Res 18, 4027-4034.

33. Shinitzky M \& Barenholz Y (1978) Fluidity parameters of lipid regions determined by fluorescent polarization. Biochim Biophys Acta 515, 367-394.

34. Van Blitterswijk WJ, Van Hoeven RP \& Van der Meer BW (1981) Lipid structural order parameters (reciprocal of fluidity) in biomembranes derived from steady-state fluorescence polarization measurements. Biochim Biophys Acta 644, 323-332.

35. Van Blitterswijk WJ, Van der Meer BW \& Hilkmann H (1987) Quantitative contributions of cholesterol and the individual classes of phospholipids and their degree of fatty acyl unsaturation to membrane fluidity measured by fluorescence polarization. Biochemistry 26, 1746-1756.

36. Sawyer WH (1988) Fluorescence spectroscopy in the study of membrane fluidity. In Advances in Membrane Fluidity, pp. 161-191 [AC Aloia, CC Curtain and LM Gordon, editors]. New York: Alan Liss.

37. Jain MK \& Wagner RC (1980) Partitioning of solutes in bilayers In Introduction to Biological Membranes, pp. 117-142 [MK Jain and RC Wagner, editors]. New York: John Wiley.

38. Carruthers A \& Melchior DL (1983) Studies of the relationship between bilayer water permeability and bilayer physical state. Biochemistry 22, 5797-5807.
39. Wilson ML \& Dahlquist FW (1985) Membrane protein conformational change dependent on the hydrophobic environment. Biochemistry 24, 1920-1928.

40. Brasitus TA \& Dudeja PK (1985) Correlation of abnormal lipid fluidity and composition on rat ileal microvillus membranes in chronic streptozotocin induced diabetes by insulin therapy. J Biol Chem 260, 12405-12409.

41. Grisham CM \& Barnett RE (1973) The role of lipid-phase transitions in the regulation of $\mathrm{Na}^{+}, \mathrm{K}^{+}$-ATPase. Biochemistry 12, 2635-2637.

42. Anner BM (1985) Interaction of $\mathrm{Na}^{+}, \mathrm{K}^{+}$-ATPase with artificial membranes. Biochim Biophys Acta 822, 319-334.

43. Tanaka R \& Teruya A (1973) Lipid dependence of activitytemperature relationship of $\left(\mathrm{Na}^{+}, \mathrm{K}^{+}\right)$-activated ATPase. Biochim Biophys Acta 323, 584-591.

44. Fortes PAG (1991) Fluorescence studies of (Na,K)-ATPase under high hydrostatic pressure. In International Symposium on Innovative Fluorescence Methodologies in Biochemistry and Medicine, September 23-26 p. 4. Rome.

45. Meddings JB, Desouza D, Goel M, et al. (1990) Glucose transport and microvillus membrane physical properties along the crypt-villus axis of the rabbit. J Clin Invest 85, 1099-1107.

46. Yeagle PL, Young J \& Rice D (1988) Effects of cholesterol on $\mathrm{Na}^{+}, \mathrm{K}^{+}$-ATPase and ATP hydrolyzing activity in bovine kidney. Biochemistry 27, 6449-6452.

47. Mooseker MS (1985) Organization, chemistry and assembly of cytoskeletal apparatus of the intestinal brush border. Annu Rev Cell Biol 1, 209-241.

48. Le Count TS \& Grey RD (1972) Transient shortening of microvilli induced by cyclohexamide in the duodenal epithelium of chicken. J Cell Biol 53, 601-605.

49. Buschman RJ (1983) Morphometry of the small intestinal enterocytes of the fasted rats and the effect of colchicines. Cell Tissue Res 231, 298-299.

50. Williamson RCN (1978) Intestinal adaptation structural, functional and cytokinetic changes. N Engl J Med 298, 1393-1402. 